\title{
O conceito de Educação em Hegel
}

Pedro Geraldo Novelli ${ }^{1}$

NOVELLI, P. G. The Hegelian concept of education, Interface _ Comunic, Saúde, Educ, v.5, n.9, p.65-88, 2001.

Education has always held the attention of philosophers. Suffice it to refer to the example of Socrates teaching the public in open spaces. His activity was an invitation to learning. The German philosopher G. W. F. Hegel (1770-

1834) also was not indifferent to this issue, even though he did not refer to it in detail in his works. However, Hegel always held positions or carried out functions related with education. Therefore, one can point at this concern in his philosophy and suggest what his possible contributions to the field were. As far as Hegel is concerned, no society can survive without education, as it is the expression of reason trying to both establish freedom and implement it as a common practice. This is what the Hegelian idea of man derives from, its being characterized by the construction of the self with its peers throughout history. This man is responsible for his destiny and for his happiness, which is not identified with any material structure. In this sense, Hegel attributes centrality to content rather than to methods and techniques. Content must be offered as a right and a need, because it is through content that man learns to be free, i.e., rational. Freedom as the purpose of education can only come about across the totality of the community, which implies in overcoming individualistic positions.

KEY WORDS: Philosophy; education; freedom; concept development.

A educação sempre mereceu atenção por parte dos filósofos. Basta citar o exemplo de Sócrates ensinando em praça pública. Sua atividade era um convite ao saber. O filósofo alemão G. W. F. Hegel ( 1770 - 1834 ) também não ficou indiferente a essa questão muito embora não tenha se manifestado detidamente sobre ela em sua obra. No entanto, Hegel sempre ocupou cargos ou desempenhou funções relacionadas à educação. Por isso é possível apontar essa preocupação em sua filosofia e sugerir as possíveis contribuições. Para Hegel não há sociedade que se sustente sem a educação, pois ela é expressão da razão que busca estabelecer a liberdade e implantá-la enquanto prática corrente. Disso deriva a concepção hegeliana de homem que se caracteriza pela construção de si com seus semelhantes através da história. Esse homem é responsável pelo seu destino e por sua felicidade que não se identifica de forma absoluta com qualquer estrutura material. Nesse sentido Hegel atribui centralidade ao conteúdo e não aos métodos e técnicas. O conteúdo deve ser ministrado enquanto direito e também necessidade, pois é por ele que o homem aprende a ser livre, isto é, racional. A liberdade como fim da educação somente se realiza na totalidade da comunidade o que implica a superação de posicionamentos individualistas.

PALAVRAS-CHAVES: Filosofia; educação; liberdade; formação de conceito.

${ }^{1}$ Professor do Departamento de Educação, Instituto de Biociências, Universidade Estadual Paulista, Unesp/Botucatu, SP. 


\section{Introdução}

Ao longo de diversas épocas a filosofia, sistematicamente considerada, referiu-se à educação tomando-a como uma questão pertinente na sociedade humana. Tome-se, como exemplos a República de Platão, a Ética a Nicômaco de Aristóteles, De Magistro de Santo Agostinho, o Emílio de Rousseau, dentre outros.

O filósofo alemão Georg Wilhelm Friedrich Hegel (1770-1834) não ficou indiferente à educação em sua época, mesmo porque os efeitos do Iluminismo na França e na Inglaterra fizeram-se sentir na Alemanha. A necessidade de libertar o homem retirando-o de sua minoridade passava pela possibilidade de recepção do saber segundo o Iluminismo. Da mente que tem gravada em si o saber em Locke a Kant que posicionava a capacidade organizadora da razão confirmava-se a aprendizagem humana. Mais particularmente na Alemanha pode-se citar Lessing com sua "Educação do gênero humano" instigando sua época pelo esforço de construção da humanidade segundo os postulados iluministas. As obras "Idéias sobre a filosofia da história da humanidade" e "Cartas para o incentivo da humanidade" de Herder, contemporâneo de Lessing, também contribuíram para criar um ambiente propício à consideração da educação. "Todos os sucessos do homem, todas as ciências e todas as artes, se estiverem devidamente fundamentadas, não terão senão outra finalidade que nos humanizar, isto é, converter em humano o não humano ou o semihumano." (Herder, 1970, p.27).

A época hegeliana ainda foi marcada pelo Romantismo que expressava grande interesse pela natureza, pelo indivíduo, pela educação popular etc. (Abbagnano e Visalberghi, 1978). Um outro contemporâneo e colega de Hegel, Schleiermacher (1957) também dedicou atenção ao problema educacional em seus "Escritos Pedagógicos" (1957). Os "Discursos à nação alemã" de Fichte e as "Lições sobre o método dos estudos acadêmicos" de Schelling são textos de maior proximidade para Hegel, posto que em sua obra ele considera tais autores detidamente.

Logo após a conclusão de seus estudos formais, Hegel trabalhou como preceptor em algumas famílias. Esse fato e sua ida para a vida acadêmica, principalmente em Berlim, contribuem para sustentar a tese da preocupação hegeliana com a educação. Por outro lado, um tratamento não explícito da educação por Hegel deve ser motivo para indagar-se porque ele não teria se debruçado sobre tal questão mais intensamente. Isso ainda conduz ao cuidado de não se "pedagogizar" o sistema filosófico hegeliano. Apesar disso tudo, é preciso reconhecer que os encargos assumidos por Hegel em instituições de ensino alemãs e o material produzido aí não deixam de guardar uma relação significativa com o que ele havia produzido até então. Provavelmente se possa falar mais tranqüilamente de uma política educacional em Hegel e que, às vezes, perpassa por aspectos assim denominados "menores" como metodologias e recursos.

Além das questões até aqui mencionadas, cabe recordar que Hegel empreendeu um esforço significativo recuperando a dialética como método e revelando sua pertinência. Não cabe mais em Hegel maniqueísmo de sorte 
alguma assim também como não cabe a polarização que desconsidera a totalidade da relação. Nesse sentido faz-se necessário cogitar sobre a dialetização da educação segundo Hegel, visto que, para ele, a totalidade do real engloba a educação. Hegel lança desafios contundentes sobre a compreensão do real e, de igual modo, tais desafios podem afetar a prática pedagógica assim como sua conceituação. Certamente seria válido investigar como a dialética hegeliana proporciona contribuições para o que ocorre em sala de aula. Aliás, é estranho dentro do hegelianismo, desvincular a sala de aula das concepções e políticas educacionais.

A prática pedagógica é motivada em Hegel por uma visão específica de homem que se vincula à época do filósofo, mas que possui traduções que the são particulares. O espírito universal é traduzido pelo espírito particular. A particularização do universal é sempre uma degradação, um empobrecimento do absoluto, mas não é senão assim que o particular pode existir. Se assim não for o absoluto deixa de ganhar consistência, existência (!), completude.

Traduzir a filosofia hegeliana para a consideração da temática educacional parece merecer atenção. Não se trata, conforme já mencionado, de pôr a aura de pedagógico no sistema hegeliano, mas buscar explicitar como a filosofia desse pensador pode fazer-se relevante para as discussões envolvendo a pedagogia. A "Fenomenologia do Espírito", escrita por Hegel em 1806, apresenta muito mais o desenvolvimento da consciência do que seu surgimento. Isso significa que não há homem, lugar por excelência da consciência, que não possua consciência ou que não partilhe da realidade do ser, ou seja, do que é. No entanto, essa existência, para Hegel, não é suficiente, pois o que se é não se resume ao presente. Por que e como superar tal estado inicial de consciência são questões que Hegel procura resolver em sua obra.

O que se assume desde já é a atualidade do sistema filosófico hegeliano e de sua pertinente contribuição para uma mais ampla compreensão da educação. Trata-se de um clássico e como tal é possível que fale aos homens de todos os tempos e, portanto, aos interessados na problemática educacional.

\section{O momento histórico}

A consideração da educação sempre foi tema da filosofia de um jeito ou de outro.

Hegel viveu numa época na qual a educação era tema tratado apaixonadamente. O Iluminismo não pode ser dissociado de sua vontade de divulgar o saber e popularizar o conhecimento. Isso está presente tanto entre os gregos como Sócrates e os sofistas como no Iluminismo europeu. A República de Platão e o Emílio de Rousseau são obras de referência que denotam a preocupação com a temática educacional.

O Iluminismo europeu mergulha na educação com os desafios lançados por uma abordagem epistemológica empirista que ressalta o papel das experiências vividas pelos homens. No entanto, o mesmo empirismo, em Locke, por exemplo, aponta para a importância da educação em elucidar o 
vivido e/ou preparar para compreendê-lo mais plenamente. Portanto, a educação adquire aqui um papel de superação em relação ao antigo regime caracterizado pela centralização do ensino e pela concentração de conhecimentos entre poucos escolhidos.

O Iluminismo na Alemanha não seguiu direção distinta apesar de suas particularidades, mas desenvolveu iniciativas que buscavam romper com um determinado estado de coisas.

Lessing é um exemplo filosófico na Alemanha do século XVIII que se empenhava em educar conduzindo os homens para os ideais iluministas. Lessing entendia que pelos erros e desvios a humanidade mesmo assim avançaria em direção à sua realização maior. Assim como a verdade revelada tornara-se pertinente e determinante para todo o gênero humano, de igual modo a educação seria relevante para um indivíduo.

O progresso humano passa para Lessing pela capacitação para a prática. Isso é proporcionado pela educação que ao melhorar os indivíduos atinge toda a humanidade.

Herder também considera a educação de forma singular, pois ela é a possibilidade de superação e melhoria da condição humana marcada por carências e limitações. O fim de toda e qualquer ciência é humanizar, isto é, promover o homem de sua condição humana menor para a maior.

Além do Iluminismo deve-se atentar ainda para a presença $e$ atuação do Romantismo que também insistia sobre o determinante papel da educação. O Romantismo constitui-se numa reação contra a frieza racionalista do Iluminismo, chamando a atenção sobre a natureza, a vida, o instinto, enfim, a sensibilidade. Desse modo pretendia-se um homem completamente realizado em todas as suas potencialidades.

Os próprios representantes do idealismo alemão atentaram para a importância da educação. Kant reconhecia que a educação estava na base de todo aperfeiçoamento humano. Fichte insiste na educação e em sua relação com a política segundo a qual poder-se-ia estabelecer o fundamento para o futuro de toda uma nação, pois assim como a Revolução na França desestruturou todo um país assim também a ausência da educação poderia significar o colapso de toda uma nação.

Fichte (1977) manifesta-se a respeito de Pestalozzi como alguém que poderia salvar a humanidade enferma pela educação.

Schelling (1984) procurou fornecer ao jovem estudante de sua época um guia sobre o estudo, o que reflete sua crença na possibilidade de uma unidade e universalidade do saber.

Schiller (1963) em sua obra "Cartas sobre a educação estética do homem" busca um caminho pela arte segundo o qual a beleza atingiria indistintamente todos os homens fazendo com que suas limitações fossem suplantadas. Goethe também não se esquece da educação, porém questiona a capacidade humana de fazer os outros à nossa imagem.

Humboldt com a criação do Ginásio, Instituto de Ensino Médio, e pela Fundação da Universidade de Berlin contribuiu significativamente para o avanço educacional em seu país. Hegel passaria a maior parte de sua vida de docência exatamente na Universidade de Berlin.

A Pedagogia ganha com Pestalozzi, Richter, Fröbel, Herbart, todos sob a 
influência de Rousseau, um grande impulso nesse momento, o que configura tal época como particularmente rica em relação às questões voltadas à educação.

Nesse contexto situava-se Hegel que iria construir uma filosofia, fruto de sua época, ou seja, resultante da história e esta impregnada pela questão educacional. Para Hegel a filosofia é a própria história concebida no pensamento e, desse modo, a educação enquanto momento da história necessariamente teria tocado seu sistema filosófico.

\section{A proposta Hegeliana}

Hegel afirmava que a filosofia é filha de seu tempo apontando, assim, a importância da história. Nesse sentido Hegel situa-se dentro do debate sobre a educação de sua época, pois, além de encontrar-se nesse contexto, toda a sua vida ficou marcada pela atividade docente. Hegel foi preceptor, professor, diretor de ginásio, conselheiro escolar, professor e reitor universitário e consultor do governo para assuntos educacionais. Hegel viveu de perto as reformas educacionais na Alemanha tanto no período do ginásio como na universidade.

Todo sistema filosófico desenvolve sua visão de como é a realidade, como esta se constitui e porque deve ser de um certo modo. Encontra-se aí uma indicação do ser e de ser. Portanto, toda filosofia propõe um procedimento para a apreensão adequada da realidade. A filosofia hegeliana considera o processo e o devir segundo os quais a realidade é o que é pela alienação, pela mediação e pelo trabalho. A realidade é processo do vir a ser, isto é, não é dada, mas vem a ser $e$, isso, constantemente. Se a realidade está sempre vindo a ser é porque ela nunca é definitivamente. Por outro lado, a realidade vem a ser porque parte de algo que se posiciona como o que ela não é, mas que também é enquanto existência que é negada, abandonada, deixada para trás.

La realidad es la unidad de la esencia y la existencia; en ella la
esencia sin configuración y la apariencia inconsistente, o sea el
subsistir sin determinación y la instable multiplicidad, tienen su
verdad. La existencia es por cierto la inmediación que há salido del
fundamento; pero todavía no há puesto en sí la forma; por cuanto
se determina y se forma, es la apariencia; y por cuanto este
subsistir, determinado sólo como reflexión en outro se perfecciona
convertiendo se en la reflexión en sí, se convierte en dos mundos,
dos totalidades del contenido, que están determinadas una como
reflejada en sí, la otra como reflejada en outro. (Hegel, 1968, p.467)

Uma realidade não dada é uma realidade não determinada, mas também não indeterminada e, caracterizada por essa perspectiva, ou seja, suspensa entre o aqui e o agora e o lá e o depois. Para Hegel o compromisso da filosofia é pensar o que é e isto significa considerar a totalidade. Cada momento é relevante, pois possibilita o seguinte, o que implica assumir a história, a 
totalidade, o que está por vir. Portanto, não se trata de reconhecer uma presença atemporal ao longo da existência humana, mas de perceber a indeterminação, o não esgotamento, na determinação histórica.

Hegel afirma que o homem é resultado da intencionalidade e isto o caracteriza. O homem é o que ele faz de si mesmo. Obviamente não há o controle ou a consciência absoluta de tudo o que o homem possa ser e fazer. As conseqüências de um ato humano não podem ser absolutamente determinadas. Assim mesmo o homem é sua própria atividade, a formação empreendida e recebida, em outras palavras, a sua educação.

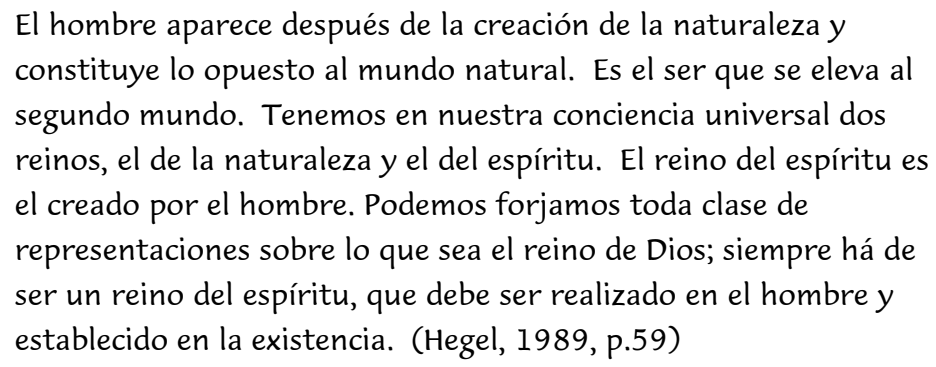

O homem não é, para Hegel, determinado totalmente pela natureza. Por isso, ele se constrói e ao construir-se realiza o espírito, por exemplo, presente na cultura de uma época e isto significa sua própria realização. Desse modo o homem participa da vida do espírito sendo ao mesmo tempo o espírito cuja indeterminação é resultado de um processo que se expressa na liberdade. Aqui não se trata de um conceito abstrato, mas da consciência de ser livre e, tal consciência, é a consciência de algo mais, de uma realidade objetiva. Portanto, trata-se de uma relação que põe, e na qual é posta, a liberdade. A liberdade, por sua vez, é atingida por um processo que exige o desensimesmamento do sujeito, do indivíduo para encontrar, reconhecer o outro, para além de si, mas que possibilita o próprio si e sua assunção. Pelo objeto, pelo outro, é que ocorre a tomada de consciência do eu. Trata-se de uma perda para que aconteça o ganho, um desencontro que resulta no encontro. Hegel condiciona a liberdade à centralidade do em si, ou seja, do sujeito, porém faz-se necessário o processo da passagem pelo para-si, no objeto, de modo que o centro seja alcançado.

Contudo, o momento da centralidade, embora seja o momento da perfeição, não se caracteriza pela inabilidade, mas, ao contrário, pela contínua atividade. Essa é a marca do espírito que existe por si porque passa pelo outro de si mesmo. As coisas naturais não existem por si, pois, diferentemente do espírito, não ultrapassam o estado ensimesmado indo em direção ao outro.

O homem, segundo Hegel, está sempre interagindo com seu meio sendo constantemente afetado pela exterioridade. Com isso o homem pode aceitar tal estímulo como determinante ou negá-lo como insignificante. Ora, o homem pode reconhecer o que lhe vem de fora e adequá-lo às suas intenções. Hegel entende que a natureza encontra-se enclausurada em determinações que lhe são intrínsecas e sobre as quais ela não exerce ação alguma. O homem pode extrapolar a determinação da necessidade $e$ 
satisfação imediatas. Essa abertura do humano à exterioridade é o que possibilita a educação, pois aqui reside a relação, o espaço da coletividade. De igual modo a sociedade torna-se uma realidade porque deixa de fundamentar-se sobre particularidades exclusivistas.

\footnotetext{
El hombre, como espíritu, no es algo inmediato, sino esencialmente un ser que há vuelto sobre sí mismo. Este movimiento de mediación es un rasgo esencial del espíritu. Su actividad consiste en superar la inmediatez, en negar esta $y$, por consiguiente, en volver sobre sí mismo. Es, por tanto, el hombre aquello que él se hace, mediante su actividad. So lo lo que vuelve sobre sí mismo es sujeto, efectividad real. (Hegel, 1989, p.64)
}

O homem é a história e, por isso é um dever ser mesmo o que pode ser. É um dever ser porque lhe é pedido que se adeque ao momento e suas circunstâncias e que as assuma como sendo de sua autoria. De forma imediata, isto é, sem mediação, o homem é tão somente a possibilidade de ser, ou seja, ser livre e racional. Contrariamente ao animal, o homem não se educa pelo seu simples "robustecimento", mas pela necessidade de ser que ele obtém pela superação do natural. Hegel alude a isso na aquisição e no desenvolvimento da disciplina que é expressão do regramento aceito $e$ cultivado.

Afirmar a historicidade do homem é afirmar sua condição de povo visto que a história nunca é atividade isolada e exclusiva de indivíduos. Assim, cada homem educa-se dentro de seu povo pelo que faz pensando em si, mas que na verdade é o pensar de um povo, do seu povo.

A consciência de agir pelo pertencer a um povo não se restringe à ação de um ensinamento ou processo educativo exterior ao indivíduo. É muito mais um agir orientado pelo contexto no qual o indivíduo está inserido. Para Hegel o que se tem aqui é a própria substância do indivíduo contra a qual não se pode lutar e que pode apresentar-se distintamente em diferentes indivíduos. Alguns indivíduos podem distinguir-se porque captaram o espírito de seu povo e não o fariam estando fora desse povo. Mesmo assim os indivíduos de maior destaque não realizam o que intencionam por si próprios, mas tão somente o que encontra eco no povo já que aí estão as condições necessárias para tanto.

Mais uma vez evidencia-se que o homem é fruto da atividade de formação da qual ele participa na vida de seu povo. Tal participação pode ser muito ou pouco percebida e o quanto é percebida determina o envolvimento com a totalidade dos indivíduos expressa na atuação do indivíduo particular. O comportamento distintivo do indivíduo marcado pela inserção e consonância com o espírito de seu povo denota seu crescente nascimento do natural ao espiritual: "El niño no es todavía un hombre racional, sólo tiene disposiciones, sólo es razón, espíritu en sí; únicamente mediante su cultura y desarollo se convierte en espíritu” (Hegel, 1992, p.123).

A religião representa o apreendido empiricamente. A representação está presa ao conteúdo sensível e a superação desse estágio manifesta-se na compreensão do representado. Todo homem apreende o mundo 
sensivelmente. Representa para si o que experimentou. A posse do apreendido que se torna saber, conhecimento exige a aquisição de forma ideal. Esta se manifesta na supressão da fragmentação, da diversidade e da particularidade. Toda experiência individual tem sua verdade na totalidade que congrega as mais diversas experiências do indivíduo e de todos os indivíduos. A diferença de apreensão e de representação reduz-se à unidade do conceito, do espírito. Tem-se aqui um procedimento metodológico pelo qual o saber é obtido. O ponto de partida é a manifestação empírica que já revela a idealidade que inclusive permite a determinação da própria empiria. A seqüência do método revela pouco a pouco a idealidade e sua universalidade. Resulta disso a mediação que Hegel coloca como fundamento do ser. O ser é um vir a ser e isso o faz conseqüência, produto, efeito. Por outro lado, o que faz a conseqüência, o que produz, o que causa, também é mediado enquanto origem através do que realiza. A mediação não se apresenta senão pela imediação. A imediação, por sua vez, não escapa da mediação, pois adquire sua expressão na sua manifestação ou no seu acontecer. Pode-se indicar aqui que em Hegel há uma insuficiência do que é em si que busca sua satisfação no reconhecimento da própria insuficiência. O homem é em si e para si e também é em si e para si no outro, pois constitui a realidade e é por ela constituído. A relação de contradição é mais uma vez evocada visto que a interdependência $e$ a complementaridade aparecem como elementos que conduzem à totalidade. Nesse sentido, a educação não é uma mera transmissão ou uma mera recepção, pois o indivíduo também já sabe e oferece, deixando de ser receptor passivo: "(...) la educación consiste en que el individuo viva en la atmósfera de su pueblo." (Hegel, 1992, p.300).

"Viver a vida de seu povo" não significa o desaparecimento do em si no para si, mas a assunção ativa e participativa da vida de seu povo. Com isso, o em si para si do indivíduo constitui o em si e para si de seu povo, estabelecendo a afirmação de si na sua negação. O eu é no tu e este, por sua vez, possibilita o eu que é também sua possibilidade. $\mathrm{O}$ eu que se reconhece afirma-se a si mesmo e, ao fazê-lo, revela que, para ser, é necessário reconhecer a si mesmo como um outro. Na medida em que o eu se reconhece, ele revela a si mesmo a limitação $e$ insuficiência de permanecer em si que pode reduzi-lo à nulidade, ao nada, à inexistência. $\mathrm{O}$ reconhecimento em si no para si, ou do eu na sua exterioridade, cria a liberdade e a garante já que funda a relação situando o eu e o outro. Para tanto o estado natural precisa ser superado na medida em que se orienta pela singularidade, pela particularidade que sobrepõe o indivíduo ao coletivo. A participação na vida do povo implica em ser educado, conduzido à eticidade desejada e, portanto, propagada. Em que pese aqui a afirmação de uma educação inconsciente, o indivíduo é determinado pela vida que vive na vida de seu povo.

O indivíduo representa para si o que na vida do povo está representado em si, isto é, a representação exige a saída do sujeito de si indo na direção do objeto para que somente então possa voltar a si $e$, liberto de si, permitirse ser em si.

A educação proporciona o segundo nascimento do indivíduo porque o 
torna autônomo, senhor de si no convívio de seu povo. A autonomia é uma conquista do indivíduo porque este precisa aderir à proposta de seu povo $e$ renunciar suas particularidades e exclusivismos. Isso não se dá no âmbito da natureza reduzida ao em si de si mesmo, ou seja, enclausurada numa existência determinada. Portanto, a educação diz respeito à existência de indivíduos e de como estes vêm a ser individualidade coletivizada $e$ coletividade individualizada.

O processo de formação do indivíduo assemelha-se ao próprio processo de formação do espírito, isto é, da vida. O primeiro momento deste é o momento da consciência como tal caracterizada pela imediatez e seu objeto como algo sensível. Essa é a consciência sensível impressionada pela multiplicidade de dados sensíveis os quais a consciência entende como exteriores a ela, mas não ainda como "ser-fora-de-si", ou seja, sabedor de si. Essa experiência do objeto assim como a vasta gama de dados empíricos recebidos por um indivíduo, apresentam-se em si mesmos e tornam-se algo. A consciência desdobra-se em percepção na medida em que reflete sobre o objeto fazendo-o uma existência sabedora de si. O objeto é afastado da consciência e compreendido mais como algo sabido do que refletido. Há uma insistência dos diferentes objetos percebidos de se restringirem a suas respectivas posições negando a constituição de algo que as aglutina numa universalidade. A síntese operada entre o sujeito e o objeto, o conhecedor $e$ o conhecido, encarna-se aqui na lei que assume as particularidades e eleva-as à totalidade. Esse é o momento do entendimento que ainda fragmenta a realidade com a pretensão de domínio.

Da superação da distinção absoluta e do conseqüente estabelecimento da complementaridade, chega-se ao reconhecimento do objeto pelo sujeito não como o outro absoluto de si:

A verdade da consciência é a autoconsciência, e esta é o

fundamento daquele, pelo que, na existência, toda a consciência de um outro objecto é autoconsciência; eu sei o objecto como meu (é representação minha), por isso, nele sei de mim mesmo.

(Hegel, 1988, § 424, p.55)

A consciência ciente de si é a autoconsciência que se reconhece no desdobramento de si mesma. Contudo, a realidade de consciência resume-se na equação do eu = eu na qual a liberdade permanece no âmbito da abstração. A realidade dessa consciência inexiste em si, pois remete à autosuficiência da consciência na identidade plena consigo mesma. A consciência compreende-se como sujeito de si já que é objeto de si, pois o que ela considera é ela mesma. Trata-se de ser por si mesma que se num primeiro momento passa pela negação de si para que se descubra no outro de si, no momento seguinte empreende a retomada de si mesma pela identificação de si com o outro de si. Ainda que o indivíduo não atinja a alteridade absoluta do objeto, porque se encontra preso à alteridade em si mesma de si próprio, a negação de si ainda não é absoluta porque o outro é a alteridade para si mesmo de um outro. O "tu" é ainda reflexo do "eu" e não um outro "eu" para além da identidade. 
Com o encontro de autoconsciências, ganha corpo o processo de reconhecimento pleno. Individualidade e coletividade iniciam suas manifestações. A perda se estabelece desde que a outra consciência não é naturalmente assimilável e não se entrega passivamente. O desconhecimento do outro, a expectativa sobre a ação do outro, o possível perigo representado pelo outro, não proporcionam qualquer segurança em relação a ele. Ao mesmo tempo ocorre o reconhecimento de si, a percepção do próprio agir e do possível dano sobre si. Esse reconhecimento de si revela também o desconhecimento de si, pois se vem a conhecer o que se é e, sobretudo, que se é. A relação está posta, mas não se explicitou ainda como ela será vivenciada ou como será estruturada. O eu-outro se articula com o outro-eu e a sociedade é gerada e adquiri expressões singulares. Mesmo as expressões balizadas pela equanimidade possuem a divisão e o desequilíbrio em seu seio porque ambas as consciências precisam ceder e escolher entre a afirmação de si no domínio contra o risco da própria existência $e$, a negação de si na subordinação pela preservação da própria existência. O jogo entre a identidade e a diferença está na raiz da relação. O reconhecimento do outro passa necessariamente pela identificação do outro e isso significa determinar, delimitar o outro de modo que possa ser relacionado, referido a um enquadramento. Apossar-se do outro é possível porque a identificação está calcada numa visão estática do que quer que se considere. O outro é e não pode deixar de ser sob pena de jamais ter sido. A realidade pode sempre ser capturada e dela pode-se ter certezas que expressam verdades. Por outro lado, o outro é reconhecido por ser distinto, diverso, como o "não-eu", pois na medida em que destoa do eu é tido como um estranho que não pertence às referências até então conhecidas e aceitas. Com o aparecimento do outro, o eu é obrigado a rearranjar sua percepção da realidade procurando localizá-lo de algum modo. Por meio desse procedimento, o próprio eu é revelado para si mesmo. Obviamente, não se trata de qualquer diferença presente nesse processo, mas da diferença levada ao extremo como absoluta. Portanto, instaura-se um conflito de vida e morte conforme o próprio Hegel o denomina. Se se estabelece um equilíbrio entre essas duas instâncias isso se deve ao fato de que o desequilíbrio está sendo superado ao mesmo tempo em que pode vir a predominar a qualquer momento. Ganhos e perdas estão envolvidos nesse processo, pois tanto o eu quanto o outro necessitam e, também são forçados, a abrir mão de seus isolamentos e, em última instância, de si mesmos. Ganhar é ganhar o outro e a si mesmo pela perda de si mesmo e perder é perder-se no outro e a si mesmo para o ganho de si. O que rege a relação é a contradição que não é contingente, mas intrínseca à relação de modo que a negação põe a afirmação evocando a extrema dinamicidade da realidade.

A diferença entre os indivíduos está na identidade, pois um aparece para o outro e nesse aparecer, nessa manifestação, está presente o que o outro é. No entanto, o outro não se resume nesse aparecer, o que indica que ele não se encontra aí totalmente. $O$ reconhecimento da universalidade na objetividade $e$ dessa naquela desemboca na consciência marcada pela razão.

A razão enquanto Idéia surge aqui na seguinte determinação: a oposição do conceito e da realidade em geral, cuja unidade é, conseguiu aqui a forma mais precisa do conceito, para si existente, da consciência e do objeto que externamente perante ela existe. (Hegel, 1988, § 437, p.60) 
A razão é a superação da dicotomia entre a universalidade e a particularidade, o sujeito e o objeto, a experiência sensível e a especulação. A consciência reconhece-se em seu objeto e se distingue dele sabendo-se nele $e$ por ele e, precisando negá-lo enquanto absoluto em si, o que implica sua concomitante negação, para chegar ao para si de si e do próprio objeto.

Para Hegel, aprender é aprender com alguém mais, por intermédio de alguém, isto é, por um processo necessariamente mediado. O indivíduo precisa passar por diversos estágios em sua formação. Tais estágios podem ser caracterizados na particularidade e na universalidade do espírito de cuja existência o indivíduo participa. O espírito se desenvolve na vida do indivíduo e o desenvolvimento do indivíduo ocorre no espírito.

A tarefa do indivíduo é adquirir o que lhe é apresentado e apropriar-se da cultura de sua época. Essa apropriação é o acesso à cultura universal da qual participam todos os povos. Conhecer e fazer seu o conhecimento construído por outros povos torna o indivíduo membro da universalidade. Desse modo, o espírito é atualizado e confirmado pelo indivíduo que, conseqüentemente, se confirma aí. O espírito não atropela o indivíduo em seu lento, porém necessário percurso porque cada etapa encerra em si a totalidade que se constrói passo a passo. O indivíduo atinge o máximo possível em cada uma das etapas, pois o que obtém está condicionado a suas capacidades e às contribuições do momento. O trabalho do indivíduo já está facilitado porque ele não precisa refazer todo o conhecimento ao qual é apresentado, mas a partir dele pode empreender sua atuação de investigação. $O$ indivíduo necessita representar a cultura adquirida e essa presentificação da cultura é a própria presentificação do indivíduo.

A pedagogia hegeliana remete muito mais a uma antropologia, ou seja, a compreensão do que é e como vem a ser o homem. O homem, em Hegel, é contínua passagem, contínuo vir-a-ser sempre filho de seu tempo, do que o precedeu e do que está por vir enquanto resultado de sua própria atividade. Certamente é dessa concepção de homem que se deve erguer toda uma proposta pedagógica que tão somente viabilize esse homem. Provavelmente por isso não se encontra em Hegel uma sistematização da questão pedagógica e talvez seja um exagero procurar remeter passagens da obra de Hegel à referida questão. No entanto, pode-se operar um esforço no sentido de pensar como a filosofia hegeliana apresenta contribuições à temática educacional.

A "Propedêutica Filosófica" de Hegel denota uma preocupação marcante com o conteúdo da prática docente sem considerar muito a questão metodológica. Há em Hegel uma certa desconfiança em relação à Pedagogia na medida em que esta se resume em formalismos, métodos e técnicas. Kant teria afirmado que não se pode aprender Filosofia, mas somente a filosofar. Hegel retrucou afirmando que aprender Filosofia seria filosofar e que filosofar estaria presente no aprender Filosofia. Para Hegel, o conteúdo torna-se determinante, pois deve ser a apresentação das verdadeiras riquezas criadas pelos homens ao longo de sua existência. Entrar em contato com isso é alçar-se à universalidade na qual reside a realização última da individualidade.

Entre 1808 e 1816 Hegel atuou como professor nomeado e reitor do 
Ginásio da cidade de Nurenberg sendo obrigado a tratar da educação mais detidamente. Nos últimos anos desse período Hegel assumiu o posto de conselheiro escolar da cidade, tornando sua relação com a educação mais estreita e explícita.

\section{A atividade de Hegel en Nurenberg}

Em 1806 Hegel deixa Iena pelas dificuldades de trabalho tanto em termos econômicos quanto intelectuais. Por intermédio de seu amigo Niethammer, assume a redação do Jornal de Bamberg no qual permanece por aproximadamente um ano. Também por ajuda desse amigo, passa a enfrentar o desafio de ensinar Filosofia para pré-adolescentes e adolescentes.

Os cursos dados por Hegel, nesse período, resultaram em sua "Propedêutica Filosófica" que são compilações feitas pelos alunos. Essas anotações revelam um esforço considerável da parte de Hegel em tentar adequar idéias da "Fenomenologia do Espírito", da "Ciência da Lógica", Enciclopédia das Ciências Filosóficas" e "Filosofia do Direito". A "Propedêutica Filosófica" indica que Hegel procurou adequar sua filosofia aos seus jovens alunos. Por outro lado, o mesmo texto mostra que ele não descuidava do conteúdo e do que seus alunos precisariam saber. Ele discorria na $5^{\text {a }}$ série do $1^{\circ}$ ciclo sobre as bases do Direito, da Moral e da Religião; nas $6^{\mathrm{a}}$ e $7^{\mathrm{a}}$ séries lecionava Lógica e Psicologia e na $8^{a}$ série revisava os temas anteriores, aprofundando-os e relacionando-os.

Por não se preocupar com os métodos de ensino, Hegel acabava por adotar o mais comum em sua época: ditava para seus alunos e em seguida fazia comentários que procuravam esclarecer. Tratava seus alunos da $8^{a}$ série por "senhor" e estimulava perguntas durante as aulas. Procurava sempre a conciliação entre os alunos, evitando toda polêmica. Hegel reconhece as dificuldades de trabalhar com os jovens e torna pública sua posição.

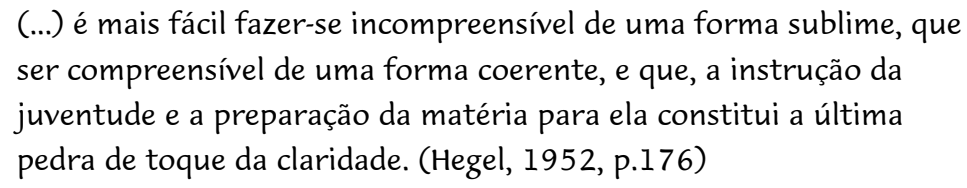

A essa dificuldade de ensinar Filosofia agrega-se a função de reitor do Ginásio que implicava a explicitação de sua compreensão do fenômeno educativo. Nesse mesmo período Hegel elabora sua "Ciência da Lógica", caracterizada pelo viés intensamente metafísico. Apesar disso, o cargo de reitor obriga-o a encarnar-se, a responder ao nível do sensível. O Ginásio já se encontrava no contexto de uma reforma educacional que se tentava implantar na Alemanha. A clientela do Ginásio possuía um perfil determinado que cultivava o humanismo com destaque para o estudo das línguas e das literaturas grega $e$ latina. Os alunos teriam propensão ao aprendizado das línguas assim como aos temas voltados à especulação $e$ ao conhecimento intelectual. A presença do mundo clássico na educação do homem ocidental sugere a recuperação da universalidade nas riquezas humanas. Certamente não é sem justificativa que Hegel enfatiza a importância do mundo grego e latino em suas "Lições sobre 
a Filosofia da História Universal”. Não há presente para um povo que não reconheça seu passado. O presente é um vir-a-ser que encontra sua razão de ser num momento superado, elevado ao além de si no momento seguinte. Daí, o passado realiza-se no presente que, por sua vez, brota do que supera.

A atenção dispensada ao ensino dos clássicos, assim como o esmero na preparação e apresentação do conteúdo, encontra eco na obra de Hegel, pois já que a verdade encontra-se no espírito, por ser este a totalidade, desvencilhada de toda determinação empírica, a adequação à prática é sinônimo de entrave para o desenvolvimento humano.

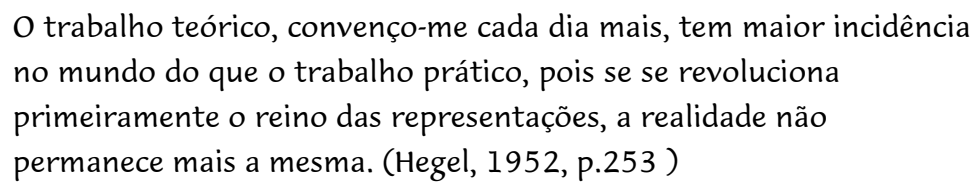

Não se deve aplicar a Hegel apressadamente a denominação de idealista absoluto por privilegiar a atividade teórica em detrimento da prática. Para Hegel não há teoria que se estabeleça senão por meio de uma prática. Hegel representa essa novidade tanto em sua época quanto em sua Filosofia, ou seja, que teoria e prática não podem ser compreendidas isoladamente uma da outra. Pelo contrário, existe uma íntima e intensa relação de complementaridade entre teoria e prática. É uma relação marcada pelo conflito em que uma pretende impor-se a outra e reinar de forma absoluta. As mudanças teóricas quando são externadas estão na realidade dando voz $e$ corpo às mudanças propiciadas e já presentes na prática. Estas, por sua vez, resultam de um esfacelamento que se opera no âmbito da teoria, pois a dissolução do que os homens pensam é a concomitante dissolução do que eles têm feito, sentido e desejado.

O que se pode inferir, apesar de tudo, sobre a postura hegeliana, é que ele insiste na contribuição que o acesso ao conhecimento acumulado pode proporcionar ao aluno. Nesse sentido, a preocupação com o conteúdo é sintomática, pois aí se encontra algo a ser sabido e ao qual se tem direito. A metodologia, a técnica adotada, o processo de comunicação desse conteúdo acaba sendo secundário. Contudo, Hegel entende que não basta comunicar, mas é necessário garantir que ocorra a comunicação. Por isso, seus cursos em Nurenberg no Ginásio foram estruturados a garantir adequação aos seus alunos assim como pôr ao alcance dos mesmos o que era comunicado.

O período de Nurenberg é significativo ainda pela assunção pública de Hegel do protestantismo. Isso ocorre numa localidade de maioria católica que olhava com suspeita a formação do ginásio. Hegel passa a identificar o protestantismo com a própria modernidade pela sua postura libertária $e$ inquiridora.

Em suas "Lições sobre a Filosofia da História Universal", Hegel aponta a passagem para a idade moderna relacionada também à corrupção e queda do domínio da Igreja Católica. A reforma insere-se nesse contexto como um movimento de superação e provocador de síntese. "(...) La Reforma como tal, el sol que sigue a la aurora del final de la Edad Media y todo lo ilumina(...)" (Hegel, 1989, p.657). O encontro com Deus passa pela natureza na medida 
em que esta é superada. Daí, a liberdade humana é uma busca interior e jamais a fixação no sensível como Lutero teria revelado. Deus é encontrado no mundo enquanto transcendência e assim é uma consciência real e do real que não se reduz à exterioridade sensível. Aqui o homem é privilegiado em relação às estruturas mesmo em se tratando de estruturas conceituais. É no coração e no espírito que se acha a salvação, a liberdade. O sensível é meio e não fim, passagem e não chegada. A fé é um salto qualitativo que reconhece a exterioridade e o que a sustenta. Por isso, vai além dela e apóia-se no que sustenta toda e qualquer exterioridade, isto é, Deus.

A superação da fixação do conceito à sua exterioridade sensível ou da subjetividade à sua objetividade resultou, na compreensão hegeliana, na extensão da liberdade a todos os homens porque a posse da liberdade não estaria mais vinculada à materialidade que se restringe a alguns indivíduos.

Se Deus se realiza em seu Filho, tal realização não é plena antes que venha o Espírito, pois este é a transcendência de toda exterioridade e a elevação desta à sua realização na interioridade. Apesar da diferença, que permite a identidade, a interioridade e a exterioridade passam a coexistir na totalidade da complementaridade entre elas. Na história persiste o conflito entre elas e a tendência mútua de uma impor-se sobre a outra, mas o conflito e a pretensão de supremacia passam a ser compreendidos como necessários e vitais. Isso traz a novidade de que a exclusão e a erradicação do outro não pode ter realização absoluta. A exterioridade no sensível, no temporal é, dentro da visão reformadora, assumida na totalidade estabelecida para com o religioso que não se desvincula daquele, mas que vê a imbricação entre ambos.

Apesar de a Reforma ter representado um avanço para a humanidade, sua mudança deu-se inicialmente pela supressão de instâncias físicas $e$ estruturais. A mudança pertinente aconteceria na assunção de uma nova ética, pois somente no nível do pensamento o significativo e pertinente tomam lugar.

Mesmo assim Hegel assume a relação entre a modernidade e a Reforma na medida em que esta é sinônimo da autonomia do pensamento moderno.

\footnotetext{
Uma grande obstinação, mas que dá honra ao homem, a de recusar reconhecer o que quer que seja dos nossos sentimentos que não esteja justificado pelo pensamento, obstinação característica dos tempos modernos. É esse aliás. o princípio do protestantismo. $\mathrm{O}$ que Lutero começara a apreender, como crença, no sentimento e no testemunho do espírito é o que o espírito, posteriormente amadurecido, se esforçou por conceber na forma de conceito para assim no presente se libertar e reeencontrar. (Hegel, 2000, p.38)
}

\section{O homem e o absoluto}

Toda concepção de educação possui necessariamente uma concepção de homem, pois o fim da educação é o homem que se deseja formar. Para Hegel, a totalidade resume-se no absoluto e o homem para ser 
compreendido enquanto tal precisa ser visto nesse contexto totalizante. $\mathrm{O}$ esforço hegeliano reside em buscar reconciliar os extremos o tempo todo. Por isso, o absoluto passa necessariamente pela história e esta se encontra fundada em sua transcendência, isto é, no vir a ser. O divino obtém consistência por ser a essência do homem e da natureza. Ser como essência do outro é o que garante a realidade do eu.

O absoluto ocorre pelo vir a ser, pela sua negação, pela manifestação da diferença no homem e na natureza que participam do próprio absoluto sendo o mesmo e não o mesmo concomitantemente.

A auto-suficiência do absoluto somente ocorre pela manifestação, do aparecer do absoluto que revela sua insuficiência não como auto-negadora, mas como mediação e condição da própria auto-suficiência. Trata-se de um movimento de reconciliação do absoluto que se abandona para tornar-se.

Enquanto consciência de si expressa, o homem apresenta-se como a mediação por excelência, pois embora o absoluto seja mediado pela natureza, esta não rompe sua determinação externa por si como projeção de sua intencionalidade.

A finitude é a diferenciação da infinitude que se nega na primeira, mas que não se anula nela. Não há identificação nem diferenciação entre o absoluto e o homem, mas a permanência da dialética entre as instâncias citadas. A universalidade é a subjetividade de cada sujeito de cada homem. É pelo espírito humano que o espírito universal adquire consciência de si. $\mathrm{O}$ homem deriva da natureza e supera tal momento na superação da existência determinada construindo sua liberdade, sua verdadeira natureza. Nesse sentido, o homem configura-se como o mediador entre o natural e o divino. Portanto, sua formação acontece pelo devir do qual comunga no absoluto.

\section{Do Estado de natureza e da Educação}

A natureza tem sido largamente citada como um antagonismo ao humano, pois é determinação e limitação que enclausura e restringe. A natureza é o reino da necessidade ao qual se opõe o homem pelo reino da liberdade. Hegel coloca a natureza como uma oposição necessária e que pela oposição será elevada além de sua determinação e limitação. A educação é o meio pelo qual o homem supera o estado de natureza o qual não pode perder de vista porque é a referência para a superação. Tanto a natureza quanto a educação são ressaltadas acentuando a tensão entre ambas.

$O$ homem existe entre a determinação do natural $e$ a indeterminação do espírito. A naturalização do espírito e a espiritualização da natureza são totalizações pelas quais o homem avança para além do imanente. A natureza está marcada pelo dever ser enquanto o homem situa-se no poder ser. A educação potencializa a dinamicidade do espírito frente à natureza que, cabe repetir, deve ser objeto de ruptura para o homem. Este deve impor limites à natureza para assim contribuir também para a transcendência da mesma.

A sociedade representa um avanço gigantesco do homem em relação à natureza $e$, socialmente, faz-se necessário o estabelecimento de condutas que sejam passíveis de serem assumidas por todos. Esse é o espaço da ética cuja construção torna-se atributo da educação. Trata-se de predispor o 
homem a um outro ser de si mesmo somente possível destoando da natureza. Portanto, Hegel não empreende a busca da harmonia entre o homem e a natureza, mas precisamente a cisão entre esses momentos que são reconciliados a partir do reconhecimento das diferenças entre si.

(...) a criança existe como homem, mas ainda de um modo imediato, natural: a educação é, em seguida, a negação deste modo natural, a disciplina que o espírito inflige a si mesmo, para se elevar a partir de sua imediatidade. (Hegel, 1991, p.123-4)

Hegel situa a infância no período da natureza. Por isso, ele realça mais a carência dessa etapa do que qualquer positividade presente aí. Comparativamente a Hegel, o pensador francês Rousseau é mais positivo e sugere a não determinação da infância por se tratar de algo pouco conhecido. Mesmo assim Hegel e Rousseau aproximam-se por apontarem a inocência da natureza presente na infância. Nesta perspectiva, a natureza tornar-se-á plena na medida em que se situa no contexto da civilização. A instauração do processo civilizatório é uma construção longa e demorada que não se estabelece pela imediatez. Toda nova geração afronta a atual $e$ surge como uma outra possibilidade. No entanto, a criança, que representa a novidade, é predominantemente dirigida pelo instinto, pela natureza. Não se sai dessa situação naturalmente mesmo porque esta tende a perpetuar-se. A natureza opera uma coação que, segundo Hegel, precisa de uma outra coação para ser vencida: “(...) tem a educação um destino negativo, (...) - o de conduzir as crianças desde a natureza imediata em que primitivamente se encontram para a independência e a personalidade livre (...)" (Hegel, 2000, p. 160).

Assim, toda educação é uma coação, pois visa libertar e promover o homem utilizando os recursos da disciplina que contribui para o ordenamento derivado da razão. Obviamente, Hegel pensa em termos de ordenamento social que não é obtido por osmose.

A liberdade absoluta $e$ irrestrita é mais perigosa e danosa para o homem que a restrição absoluta, porque a ausência de regramento resulta num estado de guerra generalizado. A pedagogia centrada na bondade natural do homem e na afirmação cabal da positividade e onipotência deste encontram em Hegel a discórdia e a contestação. O homem é o que está por vir e, nesse sentido, é indeterminação que, para superar-se, precisa atuar, agir, fazer. Isso significa que a formação humana não se limita a desenvolver as potencialidades presentes na natureza, pois esta não é o reduto do bem. A negatividade que se impõe à natureza e que media seu desenrolar é vista por Hegel como elemento primordial de toda formação. Contudo, a natureza não é também o reduto do mal, mas já guarda em si a possibilidade da liberdade porque aí a razão tem presença e manifesta-se. Apesar de tudo, Hegel insiste na relação natureza-humanidade como passagem, isto é, a natureza possibilita o estágio seguinte da humanidade que não se põe senão por meio desse expediente. Conforme mencionado anteriormente, a passagem somente ocorre por um empenho humano que empreende tal realização muitas vezes inconscientemente. Não há controle do resultado da ação 
humana que, por mais programada, intencionada e prevista que seja não pode determinar todas as repercussões possíveis. Entretanto, o homem não pode furtar-se ao trabalho de sua formação que adquire configuração maior na história. O trabalho é exclusividade humana e deve ser presença viva na existência humana concomitantemente à educação.

O espírito, é em essência, intensa dinamicidade, constante transformação, processo permanente. O trabalho é a atividade do espírito em sua individualidade que não se resigna ao imediato, ao dado estanque sendo, assim, feitor de si na sua existência. O estágio inicial da subjetividade realizase na objetividade que completa o ciclo no absoluto, porém os estágios iniciais tendem à perpetuação de si excluindo o outro. O resultado é a própria aniquilação que é evitada precisamente na abertura ao outro. Aí, o eu se encontra e se realiza. Entretanto, é pelo trabalho, por esse empenho significativo, que tal realização ganha corpo. O estudo é um trabalho exigente e que, se é possível conciliar com o prazer, não deve nortear-se pela busca do mesmo. Há sempre uma parcela de sacrifício envolvido na educação. Isso não justifica o recrudescimento dos métodos e da disciplina, mas a conscientização do processo educativo como algo que demanda compromisso, dedicação, renúncia e convívio próximo com a morte. No entanto, deve-se entender aqui que, para Hegel, a morte não tem a última palavra, mas representa o procedimento necessário para o surgimento de uma nova vida.

Educação, alienação, internalização

O desenvolvimento do espírito não é harmônico nem retilíneo, ou seja, não exclui o conflito e não avança somente pelos sucessos. Os contratempos são inevitáveis, porém eles não constituem um parêntese no processo. Os insucessos trazem em seu bojo a condição, os elementos e a referência, para os denominados sucessos.

O auge dos contratempos encarna-se na alienação do espírito. A objetivação, a exteriorização, a volta para o mundo, situam o espírito fora de si e revelam a pertinência desse abandonar-se. "Reconocer en lo extraño lo propio, y hacerlo familiar, es el movimiento fundamental del espíritu, cuyo ser no es sino retorno a sí mismo desde el ser otro" (Gadamer, 1977, p.43).

A saída de si do espírito é o que proporciona o reconhecimento de si. É o momento em que o espírito pode "olhar" para si, pode perceber-se. Porém, mais do que simplesmente perceber-se, acontece o aprendizado do espírito sobre si mesmo. Essa é a fase da interiorização. O espírito não opera unicamente uma reminiscência, mas descobre suas potencialidades, ou seja, descobre-se no vir a ser.

A realidade precisa ser entendida, segundo Hegel, como um resultado. $\mathrm{O}$ que ela é encontra-se no que será. Por isso, o início é o mais abstrato, o mais inconsistente que se revela assim ao final. De igual modo a infância é o início do humano que na idade adulta apresentará sua verdade. Cada momento supera, por incorporação, o momento precedente, o que sugere a formação do acabado e o voltar-se constantemente para o já constituído. 
O processo de alienação possui, em Hegel, a conotação "natural” do espírito que tende ao outro de si, à sua saída. O diferente é por essência atraente e chamativo e isso conduz o eu para fora de si, para o outro e por esse outro de volta para si. Pode-se identificar a diferença com profundidade, com o conhecimento do maior. Embora isso possa ser um equívoco, é inegável que produz o benefício do ir para além de si. A educação expressa-se aqui por meio da identificação e sedimentação do sujeito. Não há auto-suficiência senão pela dependência, pela aceitação da relação. Nem professor nem aluno adquirem a plenitude de suas identidades após o retorno a si, mas contribuem para que as mesmas possam ser, participando do processo.

\section{Universalidade $e$ individualização}

Toda e qualquer teoria da educação não pode deixar de apresentar sua compreensão de homem, de mundo e da relação homem-mundo. $\mathrm{O}$ homem pode ser compreendido como alguém ativo ou passivo, que já está pronto $e$ é levado a desenvolver-se ou que precisa participar ativamente de sua construção. O mundo pode ser visto como um cosmos todo ordenado ou como um caos sem ordem pré-estabelecida. A relação homem-mundo pode ser entendida como harmônica e de complementaridade ou indeterminada cuja configuração será desenvolvida na história. As teorias podem assim objetivar a integração e a adaptação do indivíduo na sociedade ou prepará-lo para interagir com a sociedade inclusive modificando-a. Tanto uma posição quanto a outra enfocam a universalidade e a individualidade, porém uma ou outra postura recebe maior consideração.

A orientação do oráculo de Delphos pelo "Conhece-te a ti mesmo" pode aludir ao esforço que o indivíduo é chamado a empreender para que daí surja sua relação com a humanidade. A valorização do indivíduo afirma o investimento sobre este que, por conseguinte, contribuiria com sua formação para a formação da humanidade. Hegel insiste exatamente no contrário, isto é, na valorização da universalidade expressa na sociedade, na coletividade que tem como resultado a individualidade enriquecida de si. Não se deve deduzir que Hegel desconsidere o indivíduo e reduza-o à totalidade do universal. Na verdade, Hegel entende que o universal $e$ o individual devem ser reconciliados e o são pelo viés da universalidade que engloba todas as individualidades, pois a percepção da individualidade já está viabilizada na própria idéia de universalidade.

A valorização da subjetividade, compreendida por Hegel, como momento da liberdade do homem moderno, garante o espaço da individualidade que, entretanto, precisa enquadrar-se na universalidade. Aqui a subjetividade e a individualidade obtêm verdade e direito, pois, por um lado, confirmam-se pela universalidade $e$, por outro, o universal recebe manifestação na alteridade desses elementos particulares. O Estado é, para Hegel, a realização suprema de todas as particularidades individuais, pois aí todos os indivíduos são contemplados e isso somente é possível porque de certa forma a individualidade não é posta como baliza.

Desse modo, o indivíduo torna-se mediação para o universal que 
impulsiona a posição hegeliana caracterizada pela paixão pela totalidade. Certamente por isso Hegel não se detém muito sobre o agir individual que é momento para algo mais pleno, é passagem para algo mais.

Esse tratamento dado por Hegel à individualidade conduz à busca do conhecimento de forma desinteressada porque as preferências $e$ necessidades individuais não podem primar sobre o processo.

O abandono das referências particulares é condição do aprender, pois, assim, ingressa-se no âmbito do universal que revela a limitação de todo particularismo calcado no interesse do singular. Como o homem é o seu outro, a sua sociedade, então ele deve nortear-se por esse procedimento $e$ interesse, ou seja, desejar o desejo do outro.

Novamente deve-se evitar a conclusão apressada da presença de uma formação despersonalizada em Hegel na qual os indivíduos seriam despojados de suas identidades. Hegel afirma a necessidade da identidade individual, pois é a partir dela que se pode elevar-se até a identidade universal. A anulação da identidade individual é o esvaziamento da universalidade. Hegel não aceita a investida exclusivista da individualidade, pois a sociedade não pode ser um conflito exacerbado, mas que recebe uma resolução. Tal resolução encarna-se no Estado ao qual os indivíduos se entregam, mas que deriva deles. Que Estado é esse? Um Estado de boas leis para o qual os indivíduos são formados.

\section{A formação humanista $e$ as exigências da modernidade}

Hegel recebeu muita influência do mundo grego e identifica este com a realização do humano. Portanto, o estudo da cultura grega expressa nas línguas, na Filosofia, parece um procedimento natural. O homem derivado do mundo grego é aquele que se embrenha pela eticidade, pela razão, pelo espírito despojado de suas contingências. Saber e conhecer o que os gregos sabiam e conheciam significava garantir a formação de homens guiados pela razão e pelo espírito.

O perigo de se estabelecer uma educação descontextualizada é, em parte, evitado por Hegel pela sua dialética que conjuga trabalho e alienação. A afirmação hegeliana de que o indivíduo é sempre fruto de sua época obriga a colocação do homem a partir de sua realidade. Além do mais, Hegel não julga adequado o retorno ao passado no qual seria encontrado o paraíso perdido. O próprio espírito, que já no início apresenta o que somente será posto ao final, deve percorrer o caminho do abandono em si por intermédio do para si para poder ser, de fato, em si, ilustra o que analogamente necessita ser realizado pelo indivíduo, pela sociedade.

O conhecimento dos clássicos já contribui para que o indivíduo deixe seu estágio natural e depare-se com as riquezas do espírito que eleva o mundo natural porque é a partir deste que ele se manifesta. Os primeiros homens (pré-socráticos) foram levados a filosofar pela admiração diante do natural $e$ procuraram razões além dessa determinação. De igual modo o ingresso no mundo do espírito merece o banho pelo espírito clássico que prepara para o mais pleno no presente.

Entre uma cultura generalizada e inconsciente de si e uma cultura erudita 
$e$ atomizada, Hegel indica a necessidade da limitação, de escolhas que renunciem à totalidade em favor da particularidade para que se possa alcançar a totalidade. Pode-se e deve-se conhecer tudo, mas não sem o regramento adequado. Os interesses devem ser limitados e contidos em sua realização para que obtenham efetividade. Desse modo, não se caminha a esmo e ao sabor dos modismos.

A will which resolves on nothing is no actual will; a characterless man never reaches a decision. The reason for indecision may also lie in a faint-heartedness which knows that, in willing something determinate, it is engaging with finitude, imposing a barrier on itself and sacrificing the infinite (...). However 'beautiful' such a disposition may be, it is nevertheless dead.

(Hegel, 1952, p. 118) ${ }^{2}$

Toda especialização, para Hegel, precisa vir acompanhada pelo enfoque humanista que oferece a visão ampla dentro da qual se localiza a especialidade. Esta jamais está isenta de oferecer uma compreensão de homem e de mundo e apresenta o sério risco de enclausurar o indivíduo em sua abordagem e de disseminar a fragmentação para a sociedade.

A ruptura em relação à especialidade se dá, segundo Hegel, pelo aprendizado das línguas, pelo trabalho e estudo para o Estado e pelos estudos dos clássicos, ou seja, o estudo humanístico. Em primeiro lugar, o estudo das línguas exige o reconhecimento da particularidade da própria língua e de que uma nova língua traz o contato com um novo povo, uma nova cultura e um momento constituinte da história. Em segundo lugar, o Estado é a totalidade que deve ser mantida pelos indivíduos, pois representa o direito de todos os limites dos governos localizados. Finalmente, a abordagem humanista visa o homem em sua completude o que põe restrições ao estudo científico-natural pela pouca exigência de sua investigação e por ser presa da imediatez. O segundo volume da "Enciclopédia" trata da natureza, mas Hegel reconhece que a juventude de seu tempo interessa-se pelas ciências naturais por entretenimento teórico. Possivelmente isso possa ser corrigido na medida em que as ciências humanas puserem suas provações ao serviço da abordagem científiconatural.

\section{A Educação e a integração no próprio tempo}

O sistema filosófico hegeliano é uma tentativa gigantesca de abraçar a realidade toda em seus mais remotos desdobramentos. Hegel está preocupado em traduzir o real no pensamento mais do que pensar o real. Sua tarefa reside em lidar com a realidade propriamente dita, e seu pensamento concentra-se sobre os acontecimentos da história humana. A filosofia hegeliana possui esta peculiaridade, isto é, procura responder às questões de seu tempo que são o resultado da atividade humana. Em sua "Ciência da Lógica", Hegel escreve que as categorias ali apresentadas são as categorias da própria realidade. Aliás, não há Filosofia que se arvore em 
espaço e momento do ilusório e do devaneio. Pelo contrário, cada uma delas pretende ser uma posição pertinente ao drama da existência humana. Hegel assume sua ligação com a realidade de forma explícita não temendo a diminuição de sua filosofia por esta envolver-se com a objetividade.

O conhecimento da língua alemã, cuja necessidade Hegel aponta, dá mostras da valorização do presente em contrapartida com sua recomendação dos clássicos. Um povo apropria-se de si na medida em que sua língua é de sua propriedade no cotidiano.

A educação deve encarnar-se em seu tempo e sua meta é favorecer o Estado e não qualquer Estado como já foi mencionado $e$, isso se traduz na criação de uma eticidade que confirme os indivíduos como cidadãos feitores de si mesmos numa instituição que seja encarnação da cidadania. Para Hegel, não há preparação para a vida e sim para uma vida qualificada, predominantemente determinada no tempo e no espaço. Os homens movidos por objetivos que transcendem o aqui e o agora, porque intentam a permanência, já se encontram inseridos no contexto do espírito e este já está, visto que precisa disso, inserido no resultado das produções humanas.

As configurações que uma sociedade adquire ao longo de sua existência já são educadoras para o indivíduo, pois, na informalidade, a forma recebe suas primeiras determinações. Isso indica para Hegel que nenhuma sociedade se sustenta sem a educação e passa a construir-se quando intencionalmente formaliza seu processo educacional e investe no mesmo.

A escola é uma particularidade do absoluto que aparece na totalidade da história humana, porém toda parte constrói a totalidade ainda que não o queira. A missão da escola é a de ser mediação entre a família e o mundo e isto implica na preparação para a vida pública. A família já é o convívio entre diferentes, mas, na sociedade, os laços que unem as diferenças superam as determinações particulares pelos elos da razão e do espírito. Contudo, a escola concilia o envolvimento com o mundo e o necessário isolamento do mesmo para que a reflexão e a investigação tenham vez.

Muito embora cada momento histórico realize sua síntese, há alguns nos quais predominam o conflito, a antítese, a objetividade em toda a sua intensidade e, assim, a quietude e o recolhimento necessários rareiam e não se pode ter perspectiva melhor do que desfrutar da preparação para $o$ festim, para o gozo, para o bem que se seguirá. É também pela educação que se adquire consciência do momento presente e de suas exigências para situar-se nele de forma pertinente.

\section{O Ensino da Filosofia}

Cabe ainda considerar a atividade docente de Hegel como professor de Filosofia que ele desempenhou durante toda sua vida.

$\mathrm{O}$ período vivido por Hegel também demonstra a resistência à Filosofia pela tendência pragmática que tinha a teoria como algo danoso. Hegel procura dar à Filosofia o lugar que lhe pertence enquanto expressão que está presente, não somente na natureza, mas também no âmbito do espírito.

Hegel está convencido de que a Filosofia, juntamente com a Arte e a Religião, é a investigação e a expressão do absoluto. A Filosofia em relação à 
Arte e à Religião seria a superação da sensibilidade e da representação pelo conceito. O conceito pode enfrentar os desafios do sensível e os questionamentos da crítica iluminista. Além do mais, a compreensão filosófica de Hegel pretende aglutinar a fragmentação das tendências filosóficas num denominador comum.

A Filosofia lida com as sombras criadas pela atividade humana tanto em seu cotidiano quanto nas ciências. Todas as ciências e o agir humano possuem um arcabouço teórico mais ou menos consciente, que serve de sustentação e de justificativa para que se faça ciência e se viva no dia-a-dia como tem sido até então praticado. Essas posturas filosóficas devem ser identificadas e assim é possível visualizar o elo que subjaz no substrato da realidade.

Comumente compreende-se a Filosofia como algo de acesso a todos o que, por conseguinte, não exigiria grandes esforços para conhecê-la, pois bastaria fazer uso da razão para emitir um juízo sobre ela. "Só para filosofar é que não se exigem nem o estudo, nem a aprendizagem, nem o esforço" (Hegel, 1988, § 5, p.73).

Contudo, a Filosofia exige empenho reflexivo e analítico, o que não se obtém preso à avalanche dos interesses materiais. Dessa forma, a Filosofia não deve sofrer uma popularização, mas o povo deveria ser elevado ao nível da Filosofia. A Filosofia possui um conteúdo significativo que deve ser apropriado pelos indivíduos, o que indica que os sujeitos filosóficos são secundários em relação ao conteúdo. Filosofar é apropriar-se de um conteúdo que é acessível pelo desenvolvimento de atitudes condizentes com o almejado. Não há diferença entre aprender Filosofia $e$ aprender a filosofar, pois somente é possível aprender a filosofar aprendendo Filosofia. Pensar ordenadamente e claramente, buscar construir o conhecimento, valorizar condutas, normatizar politicamente tais condutas, enfim, eleger o bem, o justo e o belo constituem o conteúdo da Filosofia, ilustrado nas diversas abordagens do mesmo.

Para Hegel, não se aprende Filosofia como se aprende uma outra ciência qualquer. A Filosofia demanda a radicalidade, o rigor $e$ a totalidade. $\mathrm{O}$ consenso sempre é uma posição assumida que não resolve todas as questões, embora tenha sempre a pretensão de dar conta do todo. É próprio da Filosofia o perguntar, o indagar a partir daquilo que é dado, pois este é entendido como algo passível de novas e diversas análises.

Hegel identificou sua docência com a docência universitária, o que oferece elementos interessantes sobre o ensino superior. As obras de Hegel derivadas de sua atividade na universidade, obrigaram-no a introduzir suas questões $e$ isto porque o objetivo era preparar os indivíduos para a recepção de certos conteúdos e também para o interesse por eles.

O objetivo do ensino da Filosofia aos jovens seria despertar neles o pensamento especulativo que gradualmente conduziria ao estudo sistemático da Filosofia. O sentido comum atribuído à especulação considera esta como um caminhar a esmo, sem direção e jamais atingindo uma positividade. Em Hegel, a especulação é compreendida como a síntese das determinações da reflexão e da intuição intelectual. O que Hegel pretende é a superação da dicotomia teoria-prática, análise e empiria, e isso é o que 
opera a especulação que reconhece tanto uma quanto a outra, mas que indica uma relação absoluta entre ambas. A separação entre razão $e$ sentidos, sujeito e objeto, é fictícia e pretensiosa porque afirma o caráter absoluto de um e de outro. Isso é para Hegel uma inverdade, pois não há sujeito sem objeto, isto é, a diferença é identificadora pela aproximação $e$ não pela separação.

Apesar de seu convencimento sobre a importância da Filosofia, Hegel procura adequar o conteúdo aos seus jovens alunos inclusive reduzindo o número de horas destinadas ao ensino da Filosofia. Por outro lado, Hegel julga necessário ser metódico e rigoroso em suas aulas de modo que o aluno recebesse criticamente o conteúdo que já era de posse do professor. Mesmo assim a Filosofia teria seu lugar natural na universidade pela qual se poderia esperar a sistematicidade necessária. Contudo, Hegel deparou-se com pedidos de diversas comunidades sobre a instalação do curso de Filosofia para os ginasianos, pois estes chegariam despreparados à universidade e, em particular, para o estudo da Filosofia.

A concepção hegeliana de educação precisa ser tomada em seu contexto de origem, mas deve-se reconhecer as limitações presentes nas posturas assumidas por Hegel. Entretanto, deve-se igualmente atentar para os desafios postos pela metodologia dialética em Hegel, pelas suas características de atualidade, a relação com o mundo através do trabalho; a relação entre o indivíduo $e$ a sociedade como elemento formador; a formação humanista $e$ a modernidade e a valorização do rigor e do conteúdo podem constituir aspectos que apresentem pertinência para o presente.

Referências bibliográficas

ABBAGnANO, N., VISALBERGHI, A. A história de la Pedagogia. México: Alianza Editorial, 1978. GADAMER, H.G. Verdad y método: fundamentos de uma hermenêutica filosófica. Salamanca: Siqueme, 1977.

FICHTE, J. G. Discursos a la nación alemana. Trad. M. Jesús Varela, L. Acosta. Madrid: Alianza, 1977.

HEGEL, G. W. F. The Philosophy of Right: the Philosophy of History. Trans. T.M. Knox. Chicago: Willian Benton, 1952. (Britannica Great Books, 46)

HEGEL, G. W. F. Ciencia de la lógica. Trad. A. R. Mondolfo. 2.ed. Buenos Aires: Solar/Hachette, 1968.

HEGEL, G. W. F. Enciclopédia das ciências filosóficas em epítome. Trad. A. Morão. Lisboa: Edições 70, 1988. 3 v. (Textos Filosóficos).

HEGEL, G. W. F. Lecciones sobre la filosofía de la historia universal. Trad. J. Gaos. 4. ed. Madrid: Alianza Editorial, 1989.

HEGEL, G. W. F. Introdução à história da Filosofia. Trad. A. Morão. Lisboa: Edições 70, 1991.

(Textos Filosóficos).

HEGEL, G. W. F. El concepto de religión. Trad. A. Guinzo. México: Fondo de Cultura Económica, 1992. (Colección de textos clásicos).

HEGEL, G. W. F. Princípios da Filosofia do Direito. Trad. O. Vitorino. São Paulo: Martins Fontes, 2000.

HERDER, J. G. Bildung zur Menschlichkeit. Besagt und eingeleitet von M. Mühlmeyer. Heidelberg: 
Suhrkamp, 1970.

SCHELLING, F. W. J. Lecciones sobre el método de los estudios académicos. Trad. M. A. Seijo Castroviejo. Madrid: Alianza, 1984.

SCHILLER, F. Cartas sobre la educación estética del hombre. Trad. V. Ronaro García. Madrid: Alianza, 1963. SCHIEIERMACHER, F. Pädagogische schriften. München: Suhrkamp, 1957.

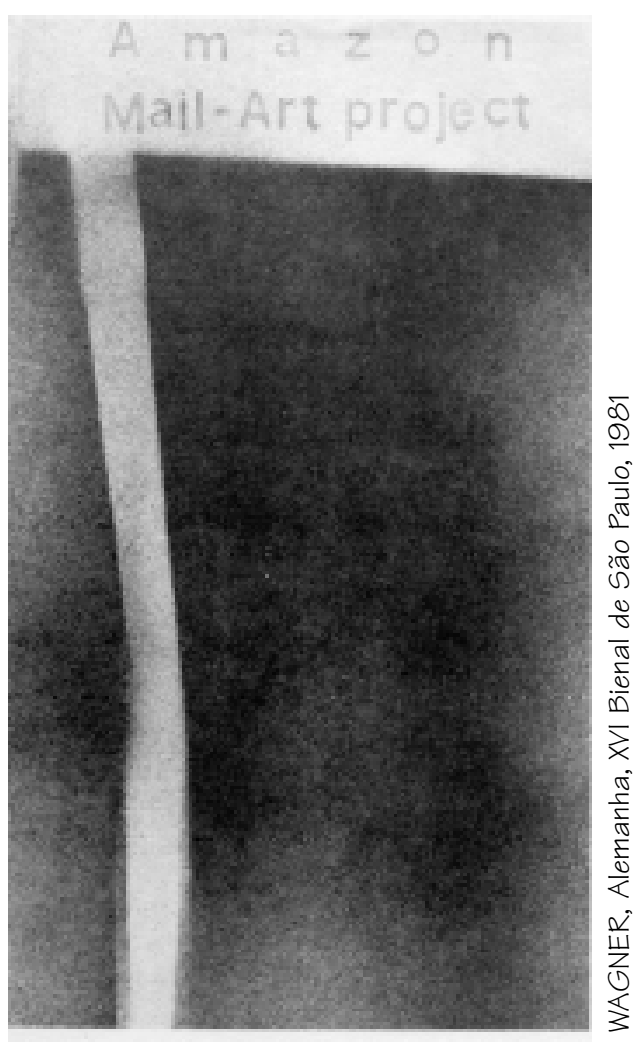

NOVELLI, P. G. El concepto hegeliano de Educación, Interface _ Comunic, Saúde, Educ, v.5, n.9, p.65-88, 2001.

La Educación siempre mereció la atención de los filósofos. Basta citar el ejemplo de Sócrates que enseñaba en plaza pública. Su actividad era una propuesta, una invitación a la sabiduría. El filósofo alemán G.W.F. Hegel (1770-1834) tampoco fue indiferente a esta cuestión, aun sin haberse manifestado exhaustivamente en su obra sobre la educación. No obstante, Hegel siempre ocupó puestos y desempeñó funciones relacionadas con la educación. Por eso es posible reconocer esa preocupación en su filosofía y así apuntar sus posibles contribuciones. Para Hegel no hay sociedad sin educación, pues ella es la expresión de la razón que intenta establecer la libertad y hacer de ella una práctica corriente. De aquí deriva la concepción hegeliana de hombre, que se caracteriza por la construcción de éste con sus semejantes a través de la historia. Este hombre es responsable por su destino y felicidad, que no se identifica en absoluto con ninguna cuestión material. En este sentido Hegel da centralidad al contenido y no al método y técnica. El contenido debe ser impartido por derecho y necesidad, pues es por él que el hombre aprende a ser libre, o sea, racional. La libertad como fin de la educación solamente se realiza en la totalidad de la comunidad, lo que implica la superación de las posiciones individualistas.

PALABRAS CLAVE: Filosofía; educación; libertad; formación de concepto.

Recebido para publicação em: 22/02/01. Aprovado para publicação em: 04/06/01 